\title{
I see what you see: the lack of a self-serving body- image bias in eating disorders
}

Citation for published version (APA):

Jansen, A. T. M., Smeets, T., Martijn, C., \& Nederkoorn, C. (2006). I see what you see: the lack of a selfserving body-image bias in eating disorders. British Journal of Clinical Psychology, 45, 123-135. https://doi.org/10.1348/014466505X50167

Document status and date:

Published: 01/01/2006

DOI:

10.1348/014466505X50167

Document Version:

Publisher's PDF, also known as Version of record

Document license:

Taverne

Please check the document version of this publication:

- A submitted manuscript is the version of the article upon submission and before peer-review. There can be important differences between the submitted version and the official published version of record.

People interested in the research are advised to contact the author for the final version of the publication, or visit the DOI to the publisher's website.

- The final author version and the galley proof are versions of the publication after peer review.

- The final published version features the final layout of the paper including the volume, issue and page numbers.

Link to publication

\footnotetext{
General rights rights.

- You may freely distribute the URL identifying the publication in the public portal. please follow below link for the End User Agreement:

www.umlib.nl/taverne-license

Take down policy

If you believe that this document breaches copyright please contact us at:

repository@maastrichtuniversity.nl

providing details and we will investigate your claim.
}

Copyright and moral rights for the publications made accessible in the public portal are retained by the authors and/or other copyright owners and it is a condition of accessing publications that users recognise and abide by the legal requirements associated with these

- Users may download and print one copy of any publication from the public portal for the purpose of private study or research.

- You may not further distribute the material or use it for any profit-making activity or commercial gain

If the publication is distributed under the terms of Article $25 \mathrm{fa}$ of the Dutch Copyright Act, indicated by the "Taverne" license above, 


\title{
Copyright (C) The British Psychological Society
}

\section{Reproduction in any form (including the internet) is prohibited without prior permission from the Society}

\begin{tabular}{r|l|l|l|l} 
British Journal of Clinical Psychology (2006), 45, I23-135 & $\begin{array}{l}\text { The } \\
\text { British }\end{array}$ \\
(c) 2006 The British Psychological Society & $\begin{array}{l}\text { Psychological } \\
\text { Society }\end{array}$ \\
\hline & www.bpsjournals.co.uk
\end{tabular}

\section{I see what you see: The lack of a self-serving body-image bias in eating disorders}

\author{
Anita Jansen*, Tom Smeets, Carolien Martijn \\ and Chantal Nederkoorn \\ Department of Experimental Psychology, University of Maastricht, \\ The Netherlands
}

\begin{abstract}
Objectives. Eating-disordered subjects feel unattractive, and the current idea is that this feeling reflects a distorted body image. A distorted body image requires a mismatch between the negative self-judgments and more objective judgments of the body.
\end{abstract}

Design and methods. To examine whether eating-disordered subjects have valid reasons for their feelings of unattractiveness, the body images of eating-symptomatic subjects and control models were compared with inter-subjective evaluations of these bodies given by two community samples (panels; $N=72, N=88$ ).

Results. Although the objective body sizes of the eating-symptomatic subjects were in the normal range and not different from control bodies, the first panel rated the (headless) bodies of the eating-symptomatic subjects as less attractive. This finding was replicated with the second panel. There was also large agreement between the eatingsymptomatic subjects and the second panel on the specific body parts that were indicated as unattractive. Contrary to the eating-symptomatic subjects, the control models showed a strong positively biased perception of their own attractiveness: they rated their own bodies more positively than others rated them.

Conclusion. Consensual validation of the harsh body appraisals of eatingsymptomatic subjects was found. Interestingly, the normal controls were the ones that showed a biased body image; they rated themselves far more attractive than other people rated them. These data suggest that the real problem in eating disorders is not a distorted body image but a lack of a distorted body image, that is, the lack of a selfserving body-image bias.

One of the main diagnostic characteristics of subjects with eating disorders is a stubborn dissatisfaction with their own body shape and weight. A general idea is that the abnormal eating behaviour follows from these feelings of fatness and unattractiveness (e.g. Rosen, 1990; Rosen, Reiter, \& Orosan, 1995), and the finding that unchanged shape

* Correspondence should be addressed to Anita Jansen, University of Maastricht, Faculty of Psychology, P.0.Box 6I 6, 6200 MD Maastricht, The Netherlands (e-mail: a.jansen@psychology.unimaas.nl). 


\section{Copyright (C) The British Psychological Society \\ Reproduction in any form (including the internet) is prohibited without prior permission from the Society}

and weight concerns after treatment predict relapse (Fairburn, Peveler, Jones, Hope, \& Doll, 1993) supports this line of reasoning.

For several decades, eating disorder experts tried to find support for the hypothesis that the body image of subjects with eating disorders is not only negative but also disturbed. With the aid of various body size estimation techniques (e.g. Ben-Tovim \& Walker, 1991), patients were invited to estimate their body dimensions and the results were contradictory: subjects with eating disorders sometimes tend to overestimate their body shape but not always, and normal female control groups also overestimate their bodies quite often, in particular when they are small-sized (Smeets, Smit, Panhuysen, \& Ingleby, 1998; Penner, Thompson, \& Coovert, 1991). The estimation methods did not convincingly show that patients are characterized by pure perceptual aberrations, and data on the perception of other objects than bodies confirm that visual perceptual processing is normal in eating-disordered subjects (Rushford \& Ostermeyer, 1997; Smeets, 1997; Szymanski \& Seime, 1997). Although there seemed to be nothing wrong with the visual perception of patients with eating disorders, the idea that the body image of subjects with eating disorders is distorted was not abandoned. Instead, the focus changed from a pure perceptual aberration to distortions in feelings and cognitions: patients with eating disorders are now supposed to erroneously feel fat and unattractive (Cash \& Deagle, 1997).

It is beyond question that patients with eating disorders are dissatisfied with their body shapes and that they feel fat and unattractive. However, the popular idea that their feelings of unattractiveness reflect a distorted body image is an assumption that has never been tested empirically. To support the assumption that the negative body images of patients with eating disorders are cognitive distortions, one should show that there is a mismatch between the negative self-views of bodies and more objective measures of these bodies. It is rather easy to determine whether one's body weight and body fat distribution is normal, but it is difficult to decide whether the attractiveness of a body is within a normal range. In the present study, we tested the correspondence between selfviews of bodies and others' views of these bodies.

To examine whether eating-disordered subjects have valid reasons for their negative body image, we compared the body images of eating-symptomatic females with objective data (body mass index and waist-hip ratio) and inter-subjective evaluations of their bodies (ratings of attractiveness given by independent observers). In line with earlier findings and clinical knowledge, we expected the eating-symptomatic group to appraise their bodies more negatively, whereas being physically attractive, beautiful and slim was expected to be more important for them than for control models. The question under study is whether there is consensual validation of the eating-symptomatic subjects' harsh appraisals. If the negative body image is a cognitive distortion, a mismatch between the negative self-views of bodies and others' views of these bodies is expected to be found.

\section{STUDY I}

\section{Method}

\section{Subjects}

Announcements at the university campus and an advertisement in a Dutch version of Cosmopolitan magazine asked for normal-weight females with and without eating problems, who were willing to be photographed in underwear without their head being 


\section{Copyright (C) The British Psychological Society \\ Reproduction in any form (including the internet) is prohibited without prior permission from the Society}

visible. The 47 subjects who replied completed the Restraint Scale (RS; see assessment) and the subjects who scored 1.5 standard deviation $(S D)$ above $(\geqq 15)$ and below $(\leqq 9)$ the mean of a Dutch sample on the RS $(N=448 ; M=12$; unpublished data) were selected for participation. This selection procedure provided for a community sample of 14 high restrained eating and 12 unrestrained eating subjects. In this paper they will be called the 'models'.

Advertisements in three local journals asked for subjects who were willing to see and judge slides. It was not mentioned what they were going to see on the slides and it was also not mentioned that the study was on eating disorders. Seventy-two local inhabitants volunteered to participate and shall hence forth be referred to as 'the panel'. The panel consisted of 21 men (29\%) and 51 women (71\%), with a mean age of 29.4 years (range 20-44). All subjects were Caucasian (95\% Dutch, the remaining 5\% from other Western European countries).

\section{Stimuli and assessment}

Stimuli

A professional photographer took the slides in a studio. The background of the slides was blue and each model was dressed in the same underwear (cream underpants and a cream bra). The model stood in a standard position with the arms hanging loosely beside the body in a frontal view. Heads were not visible on the pictures.

\section{Body image}

Each model rated the attractiveness of her own body from memory, without the aid of a photo or mirror. This rating was considered the body image. Attractiveness was rated on a visual analogue scale ranging from 0 (very unattractive) to 100 (very attractive). Moreover, she gave her body a grade for its general appearance between 0 (very negative) and 10 (very positive). The models also indicated what their most attractive and their most unattractive body parts were, with a minimum of 0 and a maximum of 5 body parts for each category.

Body ratings by the panel

The panel rated the attractiveness of the models' bodies (presented on slides) on visual analogue scales ranging from 0 (very unattractive) to 100 (very attractive). Moreover, a grade for general appearance between 0 (very negative) and 10 (very positive) was given for all bodies.

\section{Restraint}

To select participants, the Restraint Scale (RS; Herman, Polivy, Pliner, Threlkeld, \& Munic, 1978) was used. The RS is a short 10-item self-report scale assessing attitudes towards weight and eating, degree and frequency of dieting and weight fluctuations. The range of scores is 0-35; high scores reflect unsuccessful attempts to diet: subjects scoring high on the RS both attempt to restrain eating and periodically lose control (Gorman \& Allison, 1995).

\section{Eating pathology}

To measure the presence and severity of specific eating psychopathology the Eating Disorder Examination-Questionnaire (EDE-Q; Fairburn \& Beglin, 1994) was used. The EDE-Q is a valid, effective, and psychometrically sound self-report measure for the 


\section{Copyright (C) The British Psychological Society \\ Reproduction in any form (including the internet) is prohibited without prior permission from the Society}

screening of eating disorders (Luce \& Crowther, 1999; Wilfley, Schwartz, Spurrell, \& Fairburn, 1997) that was developed as a self-report version of the Eating Disorder Examination interview (Fairburn \& Cooper, 1993). The EDE-Q interview has repeatedly been found to discriminate reliably between eating-disordered subjects and normal controls (Cooper, Cooper, \& Fairburn, 1989) and also between eating-disordered subjects and dieters without eating disorders, in particular, on the three subscales eating concern, weight concern, and shape concern (Wilson \& Smith, 1989; Hay \& Fairburn, 1998). The questionnaire version consists of 36 items, within a 28-day time frame, most of them loading on one of four subscales: restraint, eating concern, shape concern, and weight concern. The restraint subscale measures the intention of the subject to restrict or avoid food intake (e.g. 'Have you gone for long periods of time (8 hours or more) without eating anything in order to influence your shape or weight?'), the eating concern subscale measures troublesome obsessions with thoughts of calories or eating (e.g. 'Has thinking about food or its calorie content made it much more difficult to concentrate on things you are interested in, for example, reading, watching TV, or following a conversation?), the shape and weight concern subscales measure troublesome preoccupation with shape and weight and the importance of body shape and body weight for overall self-evaluation (e.g. 'Has your shape/weight influenced how you think about (judge) yourself as a person?'). Furthermore, frequency ratings of key behaviours such as binge-eating, vomiting, and laxative misuse are included in the questionnaire. The EDE-Q shows excellent internal consistency and test-retest reliability (Luce \& Crowther, 1999) and is notably an acceptable alternative to clinical interviews when assessing the features of eating disorder symptomatology that are not conceptually complex or subject to definitional problems such as binge-eating (Luce \& Crowther, 1999; Carter, Stewart, \& Fairburn, 2001). In the present study the EDE-Q was used to assess eating disorder symptomatology in the present sample: the four subscale scores and the global score (i.e. the mean score of the four subscale scores) will be presented, but not the symptoms that are conceptually complex or subject to definitional problems because of decreased reliability for those items. High scores on the EDE-Q scales are related to more eating psychopathology than low scores; the high scorers are considered to be eating-symptomatic and will be referred to as the eating-symptomatic group.

The importance-of-appearance task

The models rated how important it was to be physically attractive, beautiful, and slim. First, each model had to arrange 10 general issues in order of importance (being a cheerful colleague or fellow student; being a reliable friend or partner; achieving good results, for example at school, the university or at work; having a good figure; earning a lot of money, now or later; being a good daughter; being physically attractive; being nice; being slim; being good at a hobby). These issues were ranked from 1 (most important) to 10 (least important). Then all these issues were given a rating between 0 (not at all important) and 100 (very important). In the analysis, the 1-10 arrangements of importance are called the 'rankings', whereas the 0-100 importance ratings are called the 'ratings'.

\section{Depression}

The Beck Depression Inventory (BDI; Beck, Ward, Mendelsohn, Mock, \& Erbaugh, 1961) was used to measure depression. Higher scores reflect increasing depression. 


\section{Copyright (C) The British Psychological Society \\ Reproduction in any form (including the internet) is prohibited without prior permission from the Society}

Body-image bias and eating disorders

Self-esteem

Self-esteem was determined by the Rosenberg Self-Esteem Scale (RSES; Rosenberg, 1965). The scale has high reliability and validity (Rosenberg, 1965), and consists of 10 items answered on a 4-point scale from strongly agree to strongly disagree. The range of scores is 10-40, with higher scores meaning higher self-esteem. Scores 20 or lower scores are considered low self-esteem scores by Rosenberg.

Body mass index (BMI) and waist-to-hip ratio (WHR; Singh, 1993) were used as indexes of a good figure. The BMI is the ratio of weight to squared height $\left(\mathrm{kg} / \mathrm{m}^{2}\right)$, and an index between 19 and 25 reflects a normal body weight. The ideal WHR for females is 0.7 (Singh, 1993).

\section{Procedure}

Each model was run individually. After entering the studio, her body image was assessed by means of the attractiveness VAS, the grade for general appearance and the identification of her most attractive and most unattractive body parts. Then she completed all other questionnaires and afterwards she changed clothes and the picture of her body was taken. Finally her height, weight, waist, and hips were measured and she was paid a small fee for participation.

Then, advertisements in the local newspapers invited 20- to 40-year-old people from the community to come to the university to take part in a study that was announced as 'looking at slides and filling in some questionnaires'. The people who responded $(N=72)$ participated in nine groups with a mean of eight participants per group (range 4-13). After a short instruction, the slides were presented one by one clearly visible in front of a lecture-room. Each slide was shown for 30 seconds and the order of presentation was determined by a computerized randomization procedure. For each group a new randomized order was used. Each participant rated the 26 models on the attractiveness VAS and gave her a grade for general appearance, without knowing that the slides were from eating-symptomatic models and their controls. In fact, they did not know at all that the study was about eating disorders. After rating the slides, the participants filled in a short list asking for age, gender, and nationality, and they were paid for participation.

\section{Results}

\section{Participant characteristics}

Model characteristics are shown in Table $1 ; t$ tests show that the eating-symptomatic and control models did not differ significantly in age, BMI, and WHR. The eatingsymptomatic models were more restrained and depressed than the control models. They had a lower self-esteem and showed more eating psychopathology than the control models. A high correlation between eating psychopathology (EDE-Q) and depression (BDI) was found $(r=.83)$. The EDE-Q scores of the present eatingsymptomatic models were very close to EDE-Q scores of 60 patients diagnosed as 'eating disorders not otherwise specified' (EDNOS) by Hay and Fairburn (1998).

Body image and the importance of being physically attractive, beautiful, and slim The eating-symptomatic models gave their own body a significantly lower grade for general appearance $(M=5.6, S D=1.6)$ than the control models $(M=7.1, S D=0.57)$ gave themselves, $t(24)=3.1, p<.005, d=1.25$. The eating-symptomatic models also rated themselves significantly less attractive $(M=45.4, S D=18.4)$ than the control group $(M=62.8, S D=12.7), t(24)=2.8, p=.01, d=1.8$. As expected, the present 


\section{Copyright (C) The British Psychological Society}

Reproduction in any form (including the internet) is prohibited without prior permission from the Society

Table I. Model characteristics

\begin{tabular}{lcccc}
\hline & $\begin{array}{c}\text { Eating-symptomatic models } \\
(N=14) M(S D)\end{array}$ & $\begin{array}{c}\text { Normal control models } \\
(N=12) M(S D)\end{array}$ & $t(24)$ & Cohen's d \\
\hline Age (years) & $22.4(3.7)$ & $20.8(2.1)$ & 1.3 & 0.52 \\
Body mass index (BMI) & $21.9(2.2)$ & $20.5(1.7)$ & 1.7 & 0.7 \\
Waist-to-hip ratio (WHR) & $0.7(0.03)$ & $0.67(0.05)$ & 1.6 & 0.65 \\
Restraint (RS) & $20.4(4.2)$ & $6.7(2.8)$ & $9.7^{* * *}$ & 3.77 \\
Depression (BDI) & $14.0(12.6)$ & $3.3(5.5)$ & $2.7^{*}$ & 1.07 \\
Self-esteem (RSES) & $27.3(8.0)$ & $34.8(4.3)$ & $2.9 *$ & 1.14 \\
Restraint (EDE-Q R) & $2.1(1.4)$ & $0.4(0.5)$ & $4.1^{* * *}$ & 1.57 \\
Eating concern & $1.9(1.7)$ & $0.2(0.2)$ & $3.4^{* *}$ & 1.35 \\
(EDE-Q EC) & $3.5(1.4)$ & $0.8(0.4)$ & $6.3 * * *$ & 2.52 \\
Shape concern & & & & \\
(EDE-Q SC) & $3.1(1.1)$ & $0.4(0.4)$ & $7.6 * * *$ & 3.2 \\
Weight Concern & & & & \\
(EDE-Q WC) & $2.6(1.2)$ & $0.5(0.3)$ & $6.1 * * *$ & 2.3 \\
Eating psychopathology & & & & \\
(EDE-Q global) & & & &
\end{tabular}

$\mathrm{BMI}=$ Body mass index $=$ weight in kilograms/height in meters ${ }^{2}$, WHR $=$ Waist-hip Ratio, RS = Restraint Scale, BDI = Beck Depression Inventory, RSES = Rosenberg Self-Esteem Scale, EDE-Q $\mathrm{R}=$ Eating Disorder Examination Questionnaire, restraint subscale, EDE-Q EC = Eating Disorder Examination Questionnaire, eating concern subscale, EDE-Q SC = Eating Disorder Examination Questionnaire, shape concern subscale, EDE-Q WC = Eating Disorder Examination Questionnaire, weight concern subscale, EDE-Q global = Eating Disorder Examination Questionnaire, global score. $* p<.01, * * p<.005, * * * p<.001$.

sample of eating-symptomatic models thus had a significantly more negative body image than the control models.

Table 2 shows the importance of appearance rankings and ratings. A Mann-Whitney $U$ test was used to analyse the importance of appearance data. No differences were found in the importance the eating-symptomatic models and the control models attach to being physically attractive. Clearly, both groups find it important to be physically attractive. A good figure was found to be marginally more important for the eatingsymptomatic group than for the normal control group. Being slim was, however, significantly more important for the eating-symptomatic models than for the control models. The importance of appearance data thus show that the wish to be slim is the most obvious difference between eating-symptomatic and normal control groups, whereas both groups desire to be attractive and to have a good figure.

\section{Self-views versus objective data}

The main research question is whether the negative body images reflect cognitive distortions, implicating a mismatch between the negative self-views of the eatingsymptomatic models and objective data as well as others' views of their bodies. Considering the objective data, Table 1 shows that the BMI of the eating-symptomatic group and the control group were both in the normal range (i.e. 20-25), and not significantly different from each other. Also the WHR of the eating-symptomatic group was rather ideal, and did not differ significantly from the WHR of the control group. The objective data thus do not support the negative self-views of the eating-symptomatic group. 


\section{Copyright (C) The British Psychological Society \\ Reproduction in any form (including the internet) is prohibited without prior permission from the Society}

Table 2. Rankings and ratings of the importance of being physically attractive, beautiful, and slim on the importance-of-appearance task. Ranking: 10 issues were arranged in order of importance and ranked from I (most important) to I0 (least important). Rating: the issues were given a rating between 0 (not at all important) and 100 (very important). The table only shows the rankings and ratings for the appearancerelated issues

\begin{tabular}{lccc}
\hline & $\begin{array}{c}\text { Eating-symptomatic models } \\
(N=14) \\
M(S D)\end{array}$ & $\begin{array}{c}\text { Control models } \\
(N=12) \\
M(S D)\end{array}$ & Z score \\
\hline Being physically attractive - ranking & $5.9(1.9)$ & $5.8(0.9)$ & -0.19 \\
Having a good figure - ranking & $5.6(2.3)$ & $7.0(1.3)$ & -1.6 \\
Being slim - ranking & $5.9(2.8)$ & $8.6(0.9)$ & $-2.4^{*}$ \\
Being physically attractive - rating & $69.2(24.7)$ & $65.7(18.4)$ & -1.0 \\
Having a good figure - rating & $75.6(15.6)$ & $54.2(25.7)$ & $-2.25^{*}$ \\
Being slim - rating & $71.6(19.0)$ & $44.1(26.4)$ & $-2.6^{* *}$ \\
\hline
\end{tabular}

$* p<.05, * * p<.01$.

\section{Self-views versus others' views}

Paired $t$ tests were used to test whether the panel rated the bodies of the eatingsymptomatic models unlike the bodies of the control models. Figure 1 shows that the grades given by the panel were significantly lower for the bodies of the eatingsymptomatic models $(M=6.2, S D=0.6)$ than for the bodies of the control models $(M=6.5, S D=0.5), t(71)=7.5, p<.001, d=0.89$. The bodies of the eatingsymptomatic models were also rated less attractive $(M=47.1, S D=6.4)$ than bodies of the control models $(M=51.4, S D=7.0), t(71)=4.9, p<.001, d=0.58$.

To check whether the attractiveness ratings were related to BMI, Pearson P-M correlations between attractiveness ratings and BMI were calculated. While the selfratings of attractiveness (body image) did not correlate with the model's own BMI $(r=-.18, n s)$, the attractiveness ratings given by the panel were negatively related to the model's BMI $(r=-.46, p<.02)$.

In sum, the objective data showed normal weights and good figures for both the eating-symptomatic models and the normal controls. In spite of that, the eatingsymptomatic group had a significantly more negative body image than the control models, and being slim was much more important for the eating-symptomatic models than for the control models. Interestingly, the panel rated the bodies of the eatingsymptomatic group significantly less attractive than the bodies of the control models, and they also gave the eating-symptomatic subjects a significantly lower grade for their general appearance. The attractiveness ratings given by the panel were related to the BMI of the model, whereas the attractiveness ratings of the models themselves were unrelated to their own BMI.

The inter-subjective data thus show consensual validation of the harsh body appraisals of eating-symptomatic subjects: the bodies of the eating-symptomatic models were rated less attractive than bodies of the control models.

\section{STUDY 2}

To replicate these surprising results, a second panel was invited to judge the same slides. The procedure was identical to the panel procedure in the first study, except for adding 


\section{Copyright (C) The British Psychological Society}

Reproduction in any form (including the internet) is prohibited without prior permission from the Society

Anita Jansen et al.

(a)

grade
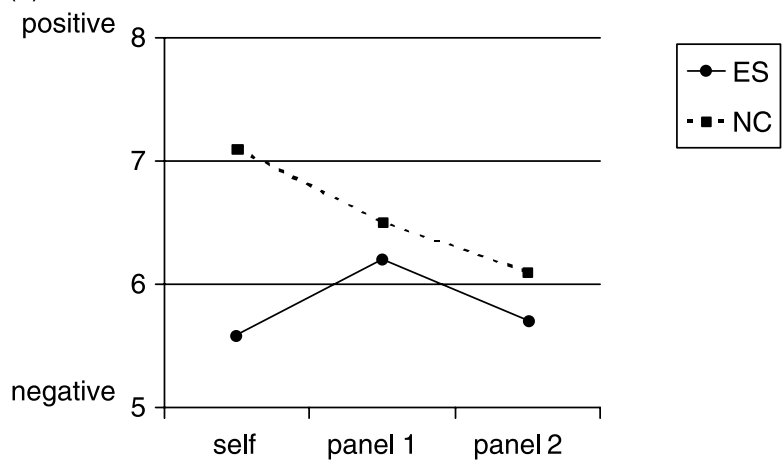

(b)

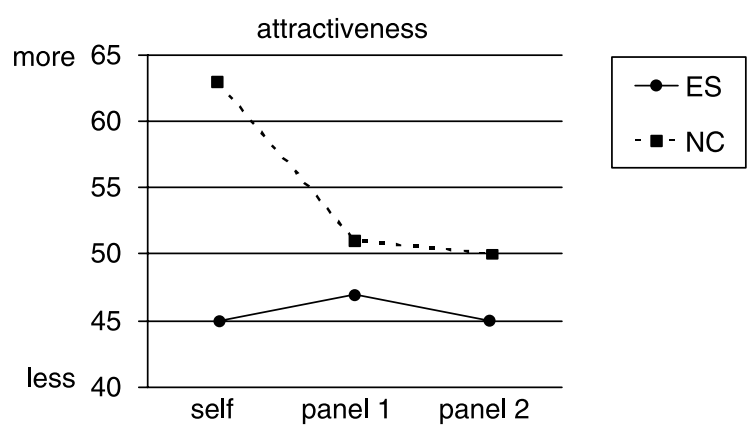

Figure I. Self-views of the eating-symptomatic and control models versus others' views. $E S=$ eatingsymptomatic models $(N=14), N C=$ normal control models $(N=12)$. Self $=$ the ratings given by the models for their own body, Panel $I=$ the mean ratings for the bodies given by the first panel $(N=72)$. Panel $2=$ the mean ratings for the bodies given by the second panel $(N=88)$. Figure la shows the grades given for the bodies (a higher grade means a more positive evaluation); Figure Ib shows the attractiveness ratings (a higher rating means a more attractive body).

one extra question: the second panel was also instructed to identify the most attractive and the most unattractive body parts of each model, with a minimum of 0 and a maximum of 5 body parts for each category.

\section{Results}

\section{Panel characteristics}

The second panel consisted of 88 individuals: 24 men (27\%) and 64 women (73\%), with a mean age of 26 years (range 18-49). All subjects were local inhabitants and Caucasian (91\% Dutch, the remaining 9\% from other Western European countries).

\section{Self-views versus others' views}

Ratings

The grades given by the second panel were again significantly lower for the eatingsymptomatic models' bodies $(M=5.7, S D=1.0)$ than for the control models' bodies $(M=6.1, S D=0.9), t(87)=4.5, p<.001, d=0.48$. The bodies of the eatingsymptomatic models were again rated less attractive $(M=45.4, S D=12.1)$ than bodies of the control models $(M=50.4, S D=11.2), t(87)=7.95, p<.001, d=0.85$. Once 


\section{Copyright (C) The British Psychological Society \\ Reproduction in any form (including the internet) is prohibited without prior permission from the Society}

Body-image bias and eating disorders

$|3|$

more, the attractiveness ratings were negatively associated with the model's BMI $(r=-.49, p<.02)$, meaning that the second panel also associated increasing BMIs with increasing unattractiveness.

To test the bias hypothesis, the models' ratings were compared with the ratings of the panels. To limit the amount of $t$ tests, the data of both panels $(N=160)$ was combined. The models' own body grades and attractiveness ratings were compared with the panels' grades and attractiveness ratings. The grades of the normal controls for their own bodies $(M=7.1, S D=0.57)$ differed significantly from the grades of the panels for the bodies of the normal controls $(M=6.3, S D=0.79), t(170)=3.65$, $p<.001, d=1.03$. Also the attractiveness ratings of the normal controls for their own bodies $(M=62.8, S D=12.7)$ differed significantly from the grades of the panels for the bodies of the normal controls $(M=50.9, S D=9.5), t(170)=4.1, p<.001, d=1.2$. Both findings indicate that the control models evaluate their own body as more attractive than others evaluate the control bodies.

Neither the grades, nor the attractiveness ratings of the eating-symptomatic group (grade: $M=5.6, S D=1.6$; attractiveness: $M=45.4, S D=18.4$ ) and the panels (grade: $M=5.9, S D=0.9$; attractiveness: $M=46.2, S D=9.98$ ) differed significantly, grade $t(172)=1.2, n s ;$ attractiveness $t(172)<1$.

The large consensus between the eating-symptomatic sample and both panels concerning the attractiveness ratings and grades for the bodies of the eating-symptomatic subjects points to a realistic body image in the eating-symptomatic sample. Both panels not only agreed with the eating-symptomatic sample, they also confirmed that the eatingsymptomatic bodies were less attractive than the bodies of control models. Further, the normal controls showed highly biased perceptions of their own attractiveness: they rated their own bodies significantly more positively than the panels rated them. This finding points to the existence of a self-serving body image bias in the normal controls.

To test whether there was a gender effect in the ratings of the panels, the ratings of the males were compared with the ratings of the females (see Table 3). To increase power, both panels were combined, ending up with 45 males and 115 females. For attractiveness, there were no differences in the ratings of males and females. Males tended to give lower grades to the normal control subjects than the females in the panels, and they awarded significantly lower grades to the eating-disordered models.

Table 3. Ratings of attractiveness and grades given by males versus females (both panels combined)

\begin{tabular}{lcrc}
\hline & Males $(N=45)$ & Females $(N=I I 5)$ & $t$ \\
\hline Attractiveness control models & $49.6(9.4)$ & $5 I .3(9.5)$ & 1.0 \\
Attractiveness eating-symptomatic models & $45.6(10.7)$ & $46.4(9.7)$ & 0.5 \\
Grade control models & $6.1(0.9)$ & $6.3(0.7)$ & $1.8^{\#}$ \\
Grade eating-symptomatic models & $5.6(0.8)$ & $6.1(0.9)$ & $2.9 * *$ \\
\hline
\end{tabular}

$* * p<.0$ I, Cohen's $d=0.33$.

${ }^{\#} p=.07$, Cohen's $d=0.53$.

Attractive and unattractive body parts

Firstly, the amount of attractive and unattractive body parts identified by the panel was counted. The panel identified significantly more attractive body parts in the normal control group $(M=1.4$ a model, $S D=0.6)$ than in the eating-symptomatic group 


\section{Copyright (C) The British Psychological Society \\ Reproduction in any form (including the internet) is prohibited without prior permission from the Society}

$(M=1.1$ a model, $S D=0.5), t(87)=7.1, p<.001$. Further, they categorized significantly more unattractive body parts in the eating-symptomatic group $(M=1.8 \mathrm{a}$ model, $S D=0.6)$ than in the normal control group $(M=1.5$ a model, $S D=0.6)$, $t(87)=8.7, p<.001$.

Secondly, consensus between the models and the panel on the identification of the attractive and unattractive body parts was measured in hits: a hit was defined as a body part indicated as attractive or unattractive by both the model and the panel. For unattractive body parts only, there were significantly more hits between the eatingsymptomatic models and the panel than between the control models and the panel: the eating-symptomatic models showed a mean of 65 hits per model (standard error $=8.7$ ), whereas the controls showed 38 hits per model (standard error $=12.9$ ). The MannWhitney test showed that the amount of hits between the eating-symptomatic models and the panel is significantly larger than the amount of hits between control models and the panel $(Z=2.2, p=.03)$. For the attractive body parts, there were no significant differences in amount of hits between a model and the panel $(Z<1)$.

Because both the panel and the model were free to mention up to five body parts in the attractive as well as the unattractive category, the chance of hits is increased when more body parts are mentioned. Therefore, the proportion of hits was also calculated. For each model the number of actual hits was divided by the sum of possible hits (i.e. the amount of body parts mentioned by the panel). The mean proportion of hits was 0.34 (SD 0.18) for the eating symptomatic models and 0.17 (SD 0.15) for the control models. This is a significant difference, $t(24)=2.6, p<.02, d=1.06$, meaning that the eatingsymptomatic models and the panel showed more agreements in their evaluation of body parts than the normal controls and the panel. Further analysis showed that the mean proportion of attractive hits was 0.27 ( $S D$ 0.2) for the eating-symptomatic models and 0.17 ( $S D$ 0.13) for the control models which is not significantly different, $t(24)=1.4$, NS. The mean proportion of unattractive hits was 0.29 (SD 0.16) for the eatingsymptomatic models and $0.16(S D$ 0.2) for the control models, which tended to be significantly different, $t(24)=1.9, p=.07, d=0.74$. The top three attractive hits for the eating-symptomatic models were: (1) breast, (2) belly, and (3) waist. Surprisingly, the top three attractive body parts for the control models was identical but in another order: (1) belly, (2) waist, and (3) breast. The top three unattractive hits for the eatingsymptomatic models were: (1) legs, (2) belly, and (3) breast. The top three unattractive body parts for the control models were: (1) legs, (2) hips, and (3) belly.

To sum up, the second panel data support the earlier findings that validate the realistic body image of eating-symptomatic subjects, and the optimistic body image of healthy control models. Moreover, these data show that there is strong agreement between the eating-symptomatic models and the panel about the models' specific body parts that are unattractive, whereas such a consensus is lacking between the panel and the control models. The specific body parts that were identified as hits were not conspicuously different for both groups of models.

\section{DISCUSSION}

The main findings of this study are twofold. First, the eating-symptomatic subjects had a rather realistic body image: there was large consensus between the eatingsymptomatic sample and both panels concerning the attractiveness of the eating-symptomatic sample. In addition, there was large consensus between the eating-symptomatic subjects and the second panel about which body parts, exactly, 


\section{Copyright (C) The British Psychological Society \\ Reproduction in any form (including the internet) is prohibited without prior permission from the Society}

were unattractive. Moreover, both panels confirmed that the eating-symptomatic bodies were less attractive than the bodies of control models, males being somewhat sterner than females. Second, the normal controls showed highly biased perceptions of their own attractiveness: they rated their own bodies significantly more positive than others rated them. This finding points to the existence of a self-serving body-image bias in the normal controls. Self-serving biases or positive illusions are prototypical for healthy people, they maintain mental health and help to protect from depression (Taylor \& Brown, 1994). Depressed people are 'sadder but wiser' (e.g. Brewin, 1993; Mezulis, Abramson, Hyde, \& Hankin, 2004) and the present data show a sadder but wiser body image in the eating-symptomatic subjects. The depressive realism model has put forward that depressed people are often more accurate and less biased in their perceptions and judgments than non-depressed people, and that just the normal subjects are prone to making biased and distorted judgments in a self-enhancing direction. Analogous, the present eating-symptomatic models were accurate in their beliefs to be less attractive than the control models, whereas the healthy controls believed they were even more beautiful than others rated them. A positive body-image bias clearly is normal and protective, whereas such a positive body-image bias is absent in eating-disorders. The present sample of eating-symptomatic models was, like most eating-disordered subjects, significantly more depressed than the healthy controls, which might have confounded the analyses. It might have been the depressed mood instead of the eating disorder that caused the lack of a self-serving body-image bias. The present data do not enable us to test this hypothesis because of extremely high correlations between the eating symptoms and depression $(r=.83)$. Eating disorder symptoms and depression are so intimately associated in this sample, that removal of variance in body-image bias associated with depression would remove nearly all variance in body-image bias associated with eating disorder symptoms (Miller \& Chapman, 2001). Covarying BDI in the present study would be like throwing away the baby with the bath water. Future studies are necessary to disentangle the contribution of depressive symptoms and eating disorder symptoms in body-image bias. It is also necessary to test whether the currently used unconventional methodology is reliable and valid, for example, by using larger samples of both the models and the panels.

Why the eating-symptomatic models were found to be less attractive than the normal control group remains an important question. Their body mass index and waist-hip ratio - as indexes of a good figure - were within the normal range and not significantly different from the normal control group, although a negative correlation was found between BMI and attractiveness ratings of the panel. Interestingly, the BMI of the model was not at all related to her self-perceived attractiveness (body image). Clearly the eating-symptomatic women's own attractiveness ratings are unrelated to their body weight. The symptomatic sample might have struggled more than the controls to keep their bodies within the normal BMI range, and their greater body dissatisfaction might thus be associated with earlier weight problems. But it is also possible that they are more dissatisfied with just the attractiveness of their bodies unrelated to body weights, for example, because they might be cursed with more unfavourable proportions between body parts, other than the waist-hip ratio. The data presented here suggest that the dissatisfaction with one's body is reasonably realistic and associated with a less attractive but certainly not too fat body. The dissatisfaction with one's body might be mistakenly transferred to body weight; the present data on the extreme importance of being slim in the eating-symptomatic group in spite of a normal weight supports this line of reasoning. Body weight might have become the focus of change because of its apparent 


\section{Copyright (C) The British Psychological Society \\ Reproduction in any form (including the internet) is prohibited without prior permission from the Society}

Anita Jansen et al.

controllability. It seems, after all, easier to do something about body weight than overly narrow shoulders, short legs, or being broad-hipped.

A prospective study of the determinants of dieting behaviour among school-going children by Stice and co-workers (Stice, Mazotti, Krebs, \& Martin, 1998) shows that dissatisfaction with one's own body is the best predictor by far of dieting behaviour. Importantly, the dissatisfaction with one's body was not strongly associated with actually being overweight. In fact, a heavier body weight predicted dieting behaviour to only a very small extent or not at all. These findings suggest that the importance attached to thinness and the conviction of being fat may be a consequence of dieting rather than the reverse, and support the present idea of a body dissatisfaction transfer to the body weight. Body-dissatisfied subjects might focus on weight because of their idea that weight is easily changeable. Further body-image research should test this hypothesis and concentrate on the role of factors that are not directly related to weight, like body part characteristics and the attractiveness of body part proportions.

Finally, if the lack of a self-serving body-image bias is indeed found to contribute to the maintenance or origin of eating disorders, interventions should better be aimed at the learning or training of a self-serving body-image bias in eating-symptomatic subjects than trying to reduce a (non-existing) distorted body image (see also Jansen, Nederkoorn, \& Mulkens, 2005). It may be an exciting enterprise to test whether training a positive self-serving body-image bias reduces body dissatisfaction, and if the early learning of an optimistic self-serving body bias is able to prevent body dissatisfaction.

\section{Acknowledgements}

Thanks are expressed to Annemiek Dobbelaar, Rilana Cima, Conny van den Heuvel, Jeannie Janssen, Wanda Moonen, and Susanne Schoemans for their help in data acquisition. Fren Smulders and Willem Hofstee are greatly acknowledged for inspiring discussions.

\section{References}

Beck, A. T., Ward, C. H., Mendelsohn, M., Mock, J., \& Erbaugh, J. (1961). An inventory for measuring depression. Archives of General Psychiatry, 4, 561-571.

Ben-Tovim, D. I., \& Walker, M. K. (1991). The development of the Ben-Tovim Walker Body Attitudes Questionnaire (BAQ), a new measure of women's attitudes towards their own bodies. Psychological Medicine, 21, 775-784.

Brewin, C. R. (1993). Cognitive foundations of clinical psychology. Hove: Erlbaum.

Carter, J. C., Stewart, D. A., \& Fairburn, C. G. (2001). Eating disorder examination questionnaire: Norms for young adolescent girls. Behaviour Research and Therapy, 39, 625-632.

Cash, T. F., \& Deagle, E. A. (1997). The nature and extent of body-image disturbances in anorexia nervosa and bulimia nervosa: A meta-analysis. International Journal of Eating Disorders, 22, 107-125.

Cooper, Z., Cooper, P. J., \& Fairburn, C. G. (1989). The validity of the Eating Disorder Examination and its subscales. British Journal of Psychiatry, 154, 807-812.

Fairburn, C. G., \& Beglin, S. J. (1994). The assessment of eating disorders: Interview or self-report questionnaire? International Journal of Eating Disorders, 16, 363-370.

Fairburn, C. G., \& Cooper, Z. (1993). The eating disorder examination. In C. G. Fairburn \& G. T. Wilson (Eds.), Binge eating: Nature, assessment and treatment (12th ed., pp. 317-360). New York: Guilford. 


\title{
Copyright (C) The British Psychological Society
}

\author{
Reproduction in any form (including the internet) is prohibited without prior permission from the Society
}

Fairburn, C. G., Peveler, R. C., Jones, R., Hope, R. A., \& Doll, H. A. (1993). Predictors of twelvemonth outcome in bulimia nervosa and the influence of attitudes to shape and weight. Journal of Consulting and Clinical Psychology, 61, 696-698.

Gorman, B. S., \& Allison, D. B. (1995). Measures of restrained eating. In D. B. Allison (Ed.), Handbook of assessment methods for eating behaviors and weight-related problems. California: Sage.

Hay, P., \& Fairburn, C. G. (1998). The validity of the DSM-IV scheme for classifying bulimic eating disorders. International Journal of Eating Disorders, 23, 7-15.

Herman, C. P., Polivy, J., Pliner, P., Threlkeld, J., \& Munic, D. (1978). Distractability in dieters and nondieters: An alternative view of externality. Journal of Personality and Social Psychology, $36,536-548$.

Jansen, A., Nederkoorn, C., \& Mulkens, S. (2005). Selective visual attention for ugly and beautiful body parts in eating disorders. Behaviour Research and Therapy, 43, 183-196.

Luce, K. H., \& Crowther, J. H. (1999). The reliability of the eating disorder examination - selfreport questionnaire version (EDE-Q). International Journal of Eating Disorders, 25, 349-351.

Mezulis, A. H., Abramson, L. Y., Hyde, J. S., \& Hankin, B. J. (2004). Is there a universal positivity bias in attributions? A meta-analytic review of individual, developmental, and cultural differences in the self-serving attributional bias. Psychological Bulletin, 130, 711-747.

Miller, G. A., \& Chapman, J. P. (2001). Misunderstanding analysis of covariance. Journal of Abnormal Psychology, 110, 40-48.

Penner, L. A., Thompson, J. K., \& Coovert, D. L. (1991). Size estimation among anorexics: Much ado about very little? Journal of Abnormal Psychology, 100, 90-93.

Rosen, J. C. (1990). Body image disturbances in eating disorders. In T. F. Cash \& T. Pruzinsky (Eds.), Body images. Development, deviance and change (pp. 190-214). New York: Guilford.

Rosen, J. C., Reiter, J., \& Orosan, P. (1995). Assessment of body image in eating disorders with the body dysmorphic disorder examination. Behaviour Research and Therapy, 1, 77-84.

Rosenberg, M. (1965). Society and the adolescent self-image. Princeton, NJ: Princeton University Press.

Rushford, N., \& Ostermeyer, A. (1997). Body image disturbances and their change with video feedback in anorexia nervosa. Behaviour Research and Therapy, 5, 389-398.

Singh, D. (1993). Body shape and women's attractiveness. The critical role of waist-to-hip ratio. Human Nature, 4, 297-321.

Smeets, M. (1997). The rise and fall of body size estimation research in anorexia nervosa: A review and reconceptualization. European Eating Disorders Review, 5, 75-95.

Smeets, M., Smit, F., Panhuysen, G., \& Ingleby, D. (1998). Body perception index: Benefits, pitfalls, ideas. Journal of Psychosomatic Research, 44, 457-464.

Stice, E., Mazotti, L., Krebs, M., \& Martin, S. (1998). Predictors of adolescent dieting behaviors: A longitudinal study. Psychology of Addictive Behaviors, 12, 195-205.

Szymanski, L. A., \& Seime, R. J. (1997). A re-examination of body image distortion: Evidence against a sensory explanation. International Journal of Eating Disorders, 21, 175-180.

Taylor, S. E., \& Brown, J. D. (1994). Positive illusions and well-being revisited: Separating fact from fiction. Psychological Bulletin, 116, 21-27.

Wilfley, D. E., Schwartz, M. B., Spurrell, E. B., \& Fairburn, C. G. (1997). Assessing the specific psychopathology of binge eating disorder patients: Interview or self-report? Behaviour Research and Therapy, 35, 1151-1159.

Wilson, G. T., \& Smith, D. (1989). Assessment of bulimia nervosa: An evaluation of the eating disorders examination. International Journal of Eating Disorders, 8, 173-179.

Received I 7 July 2003; revised version received I December 2004 